\title{
A abstração do risco e a concretude dos sujeitos: uma reflexão sobre os comportamentos de risco no contexto da adolescência
}

I ${ }^{1}$ Isabela Vilela Chimeli, ${ }^{2}$ Maria José Nogueira, ${ }^{3}$ Denise Nacif Pimenta, ${ }^{4}$ Virgínia Torres Schall I

Resumo: Em tempos em que se multiplicam as enfermidades decorrentes de hábitos de vida poucos saudáveis, característicos do estilo de vida moderno, a noção de comportamento de risco faz-se cada vez mais presente no discurso e nas práticas em saúde. No contexto da adolescência, esse tema vem sendo estudado através de investigaçōes relacionadas ao consumo de álcool e outras drogas, ao tabagismo, à alimentação inadequada, ao sedentarismo, à atividade sexual desprotegida, entre outros comportamentos que, observados entre os adolescentes, somam-se ao risco atribuído a essa fase do desenvolvimento. Este artigo objetiva discutir criticamente a construção do risco e da adolescência enquanto objetos de investigação e intervenção na área da saúde, a partir de um estudo qualitativo realizado por meio de entrevistas em profundidade com 12 adolescentes de Lagoa Santa, Minas Gerais. Os resultados apontam para diferentes aspectos pessoais e emocionais geralmente não contemplados nas pesquisas na área, que, no entanto, influenciam sobremaneira as condutas dos adolescentes. Concluise que, para o aprimoramento e a resolutividade das políticas públicas e ações voltadas para a temática dos comportamentos de risco, torna-se necessário ampliar o escopo de investigaçôes sobre os riscos e as perspectivas teóricas que lhes dão sustentação.

> Palavras-chave: comportamento de risco; adolescência; Saúde Coletiva.

\author{
1 Centro de Pesquisas \\ René Rachou - LAESA, \\ Belo Horizonte-MG, Brasil \\ (isabelachimeli@gmail.com). \\ 2 Fundação João Pinheiro - \\ Belo Horizonte-MG, Brasil \\ (mariajose.nogueira@fjp. \\ mg.gov.br). \\ ${ }^{3}$ Centro de Pesquisas \\ René Rachou - LAESA, \\ Belo Horizonte-MG, Brasil \\ (pimentadn@gmail.com). \\ ${ }^{4}$ Centro de Pesquisas \\ René Rachou - LAESA, \\ Belo Horizonte-MG, Brasil \\ (virginiaschall@gmail.com).
}


Em maio de 2014, a Organização Mundial de Saúde (OMS) divulgou um relatório dedicado à saúde dos adolescentes, atentando para a urgente necessidade de garantir-lhes melhores condiçôes de vida. Estima-se a morte de 1,3 milhão de adolescentes no mundo em 2012, em sua maioria por causas que poderiam ter sido evitadas e tratadas (OMS, 2014).

Tal cenário invoca a ampliação de conhecimentos que possam auxiliar na construção de políticas públicas e ações afinadas com as particularidades desse grupo populacional, que compreende a faixa etária de 10 a 19 anos (OMS, 2014). Observa-se, nesse sentido, um interesse crescente na produção de informações estatísticas relacionadas à saúde do adolescente, onde se inserem as concepções e investigaçõos sobre os comportamentos de risco em saúde.

A abrangência e complexidade desse grupo populacional abarcada na geração de grandes bancos de dados, porém, confronta-se com a configuração particular dos processos de saúde e doença na singularidade dos contextos. Uma importante ressalva que vem sendo feita à produção de conhecimentos sobre o risco no campo da saúde refere-se ao descolamento da produção de dados das conjunturas às quais depois retornam como informações (AYRES et al., 2009; CASTIEL et al., 2010). Faz-se assim necessário analisar criticamente uma série de questôes suscitadas pelos comportamentos de risco enquanto objeto de investigação epidemiológica, atentando para os limites interpretativos intrínsecos a esses modelos de investigação.

Este artigo é resultado de uma dissertação de mestrado que teve como objetivo compreender melhor as motivações envolvidas na adoção de comportamentos considerados de risco entre adolescentes do município de Lagoa Santa, Minas Gerais. Com intuito de subsidiar essa investigação, bem como contribuir para a discussão dessa temática em outros contextos, realizamos um estudo teórico sobre a noção de comportamentos de risco em saúde. Trata-se de um dos eixos do projeto "Adolescência e saúde: um estudo sobre comportamentos de risco no Município de Lagoa Santa-MG”, vinculado ao Laboratório de Educação em Saúde e Ambiente do Centro de Pesquisas René Rachou (CPqRR) e realizado em parceria com o Observatório da Juventude da Fundação João Pinheiro do Estado de Minas Gerais e Conselho Municipal de Juventude de Lagoa Santa (Conjuve). O projeto foi aprovado pelo Comitê de Ética em Pesquisa do CPqRR sob o número 2333.9213.9.0000.5091. 


\section{Percurso metodológico}

Nesse amplo cenário de pesquisa realizado no município de Lagoa Santa, região metropolitana de Minas Gerais, objetivou-se a realização de uma pesquisa que pudesse informar a elaboração de ações voltadas para o público adolescente local. Nosso eixo específico voltou-se para uma reflexão crítica sobre a noção de comportamento de risco na adolescência, com o objetivo de enriquecer as perspectivas que serão adotadas nas políticas públicas inspiradas no projeto. Pretendemos, portanto, com a revisão teórica e a pesquisa qualitativa presentes, atentar para as dimensões dos comportamentos compartilhados pelos adolescentes geralmente desconsideradas nas estratégias de saúde voltadas para a temática dos comportamentos de risco.

A fase de campo foi realizada durante o mês de outubro em uma organização não governamental local, o Instituto Promover. Teve 12 participantes de 14 a 18 anos cujos critérios de inclusão foram: estar cursando o ensino médio em escolas públicas do município de Lagoa Santa; aceitar o convite para a participação definido através de sorteio; e ter consigo o Termo de Consentimento Livre e Esclarecido (TCLE) assinado pelo aluno ou pelos pais ou responsáveis (para os menores de idade), no dia da entrevista. Como nossa discussão está inscrita na particularidade dos sujeitos, a lógica da amostragem representativa não se aplicou a este estudo (MINAYO, 2010).

Foram realizadas entrevistas em profundidade, a partir de um roteiro semiestruturado com algumas questôes centrais, mas flexível e subordinado à dinâmica imposta pelo diálogo entre pesquisador e participante (SCHRAIBER, 1995). As entrevistas duraram de 25 a 60 minutos. Para a análise das entrevistas, as falas foram transcritas e sistematizadas de acordo com as etapas (pré-análise, exploração do material e interpretação e inferência) propostas por Bardin (1997). No presente artigo, exploramos os temas do uso de álcool e outras drogas e da não utilização de métodos preventivos nas relações sexuais. As falas dos entrevistados foram organizadas e analisadas a partir das seguintes categorias: a) definição de drogas; b) percepção sobre drogas ilícitas; c) motivação para uso de álcool; d) motivação para uso de outras drogas; e e) motivação para a não utilização de métodos contraceptivos. 


\section{Quadro conceitual}

\section{A abstração do risco}

A busca por explicações relacionadas à configuração dos processos de saúde e doença suscitou diferentes concepções ao longo da história do pensamento humano. Grosso modo, da profunda mudança cultural que marcou o século XVI até os dias de hoje, as teorizações vêm girando em torno de duas ordens principais. Por um lado, a ênfase é colocada nos indivíduos (ou organismos) enquanto objeto de intervenção; por outro, o foco está no ambiente (natural, social, cultural) por onde circulam.

A tensão entre esses dois polos é intrínseca à operação, característica da modernidade, que separa a "ordem humana" tanto do que seria uma "ordem natural" quanto da "ordem divina", que fundamentava a visão e organização do mundo europeu nos séculos anteriores ao que conhecemos por Renascimento. Nesse período, o homem surge como força criativa independente dos desígnios de Deus, afirmando-se como aquele que, dotado de razão, poderia conhecer, moldar e apropriar-se da natureza (LUZ, 1988).

$\mathrm{Na}$ medida em que essa nova forma de observar o universo se difundia e consolidava, a tendência do pensamento ocidental foi destrinchar o mundo, até então apreendido como um todo integrado, em uma série de dualismos dicotômicos (natureza-homem; objeto-sujeito; matéria-espírito; quantidadequalidade; organismo-mente; corpo-alma; razão-emoção; etc.) e, portanto, irreconciliáveis (LUZ, 1988). Quando a ciência se firma como modelo de produção do saber no Ocidente, essas dualidades se aprofundam nas diferentes especialidades analíticas em que os fenômenos do mundo foram desmembrados, viabilizando os valores de clareza, distinção e precisão do pensamento científico.

Nesse contexto, o olhar mecanicista característico do pensamento científico tornou o organismo humano comparável às máquinas construídas pelo homem, concebendo o funcionamento do corpo a partir do desempenho de suas partes. Para tanto, foi fundamental o desenvolvimento da fisiologia e da experimentação biomédicas, possibilitadas pelo conceito de "meio-interno" estabelecido no século XIX. Tal noção referia-se à concretude dos tecidos, e mais tarde das células, onde aconteciam as reações físico-químicas do corpo humano (CZERESNIA et al., 2013), postulando-se uma independência relativa das funções orgânicas em 
relação às flutuações do meio ambiente (SAFATLE, 2011). Assim, partindo-se

da ideia de um organismo estável, foi sendo estabelecida a funcionalidade normal da mecânica corporal, e os aspectos do humano que não puderam entrar na formalização da estrutura orgânica tornaram-se objetos das ciências humanas e psicológicas (SAFATLE, 2011).

Há, portanto, uma ruptura entre corpo e espaço que está na base do desenvolvimento da Medicina moderna e que alicerça seu campo de investigações (CZERESNIA, 2012). Até o século XIX, a apreensão natural, objetiva e material do corpo humano concorria com abordagens que trabalhavam o natural e o social em conjunto, como o eram, por exemplo, a tradição higienista e a Medicina Social, cujas preocupações centravam-se no impacto das condições de vida e trabalho na ocorrência das doenças. Porém, na medida em que o corpo foi sendo minuciosamente esquadrinhado pela racionalidade científica, a busca por determinações causais específicas, localizáveis e generalizáveis se sobrepôs à constituição difusa e relacional das perspectivas mais integrativas.

Essa tendência se consolida com os desenvolvimentos da bacteriologia na primeira metade do século $\mathrm{XX}$, quando se tornou possível a associação das doenças transmissíveis a micro-organismos específicos. A descoberta de germes e bactérias, porém, não foi suficiente para determinar a origem das doenças, já que a presença de um agente causal não acarretava, necessariamente, a doença infecciosa a ele associada, tampouco especificava a gravidade do adoecimento (CASTIEL et al., 2010). Tal constatação impulsionou a utilização da estatística para estimar a probabilidade da interferência de outros fatores nos processos de adoecimento, e é nesse contexto que a noção de fatores de risco adquire centralidade no campo da Epidemiologia (CZERESNIA, 2012).

O caráter pragmático e probabilístico do risco, através de sua quantificação, permitiu à Epidemiologia expandir seu campo de investigação de forma potencialmente ilimitada, na medida em que passou a ser possível investigar associações causais entre quaisquer eventos de interesse prático para a saúde (AYRES et al., 2009). Por outro lado, a busca por explicações sobre a configuração das doenças através de procedimentos matemáticos tendeu a desvincular cada vez mais as causas de seus contextos, atribuindo às doenças e aos riscos de adoecimentos uma espécie de existência autônoma (CAMARGO JUNIOR, 1993; CASTIEL et al., 2010). 
$\mathrm{O}$ postulado de independência entre corpo e espaço permitiu à Medicina moderna desenvolver-se predominantemente fora dos ambientes em meio aos quais vivem e transitam os indivíduos, privilegiando determinadas relações em detrimento de outras no estudo dos processos de saúde e doença.

Nas práticas de pesquisa correntes, a desvinculação dos organismos de seus contextos vitais e de suas redes de correlaçóes, com o controle estatístico das variáveis de estudo, criam obstáculos para um entendimento mais amplo dos quadros de adoecimentos, e por extensão, para a resolutividade das propostas de intervenção. No âmbito das doenças crônico-degenerativas, esses impasses se radicalizam. Embora, de um modo geral, as pessoas estejam informadas sobre os riscos à saúde envolvidos em hábitos poucos saudáveis de vida, a informação não têm sido suficiente para promover a mudança de comportamento, inclusive nos meios escolarizados onde o acesso à educação não se apresenta como um empecilho (CHOR, 1999). Quando não considerada a diversidade dos aspectos que compõem a conduta humana, os dados sobre os comportamentos de risco, abstraídos da complexidade que os configuram, tornam-se assim dificilmente traduzíveis em ações eficazes.

No contexto da adolescência, à abstração do risco soma-se a construção, também abstrata, do período da adolescência, fundamentando ações orientadas pela noção de comportamento de risco que, como se destacará nos resultados da pesquisa de campo, não necessariamente correspondem às vivências e necessidades concretas dos adolescentes.

\section{$\mathrm{O}$ risco da adolescência}

A adolescência, enquanto dimensão específica da existência humana, tornou-se objeto de preocupação científica há relativamente pouco tempo. A Medicina, em sua dupla perspectiva de técnica aplicada e de produção de conhecimento, começa a ocupar-se do assunto mais sistematicamente em torno da década de 1970. Ainda que recentes, as práticas voltadas para a saúde do adolescente têm assumido rapidamente um papel destacado na literatura especializada do campo médico de todo o Ocidente (AYRES, 1990).

É notável também a rapidez com que o discurso da Medicina sobre a adolescência assumiu um caráter universal, tendo o critério cronológico como base de sua definição objetiva. Determinada, principalmente, a partir dos 
aspectos mensuráveis das modificações do corpo, essa demarcação subordina

uma série de eventos psicológicos, afetivos e sociais à dimensão somática. Embora tais elementos não sejam negados,

só a partir das transformações físicas se tomará a preocupação com as demais condições ligadas à adolescência, sem que estas tenham sua gênese ou seu desenvolvimento na dependência direta daquelas" (AYRES, 1990, p. 146).

O paradigma biomédico descreve a adolescência como uma fase de transição do desenvolvimento humano pela qual todos devem passar. Ocorrendo na segunda década de vida, entre a infância e a vida adulta, esses anos são considerados cruciais para a maturação biopsicossocial dos indivíduos, dados os processos de definição de identidades (social, sexual, profissional, política, de valores, etc.) que o caracterizam. Sendo também marcado por um turbilhão de hormônios e experiências, cria-se uma imagem desse período que beira o patológico.

Universalizada e naturalizada a adolescência nesse tipo de concepção, ainda que reconhecendo o componente social, os adeptos de tal paradigma, ao se depararem com adolescentes concretos, têm seu olhar direcionado, de antemão, segundo um padrão de adolescente, que corre o risco de se perder pelas crises que enfrenta nesse período e, portanto, pela situação de fragilidade em que se encontra - o substrato de vulnerabilidade -, na linguagem epidemiológica (PERES; ROSENBURG, 1998, p. 63).

Tanto pelos problemas de saúde que se fazem presentes durante esse tempo da vida, quanto pelos agravos que os comportamentos adquiridos podem suscitar no futuro, a adolescência é tomada como um momento crítico para as intervenções em saúde. No modelo clínico de trabalho, os componentes psíquicos e sociais passam por um processo de "naturalização", ao serem reificados numa espécie de cultura adolescente que determinaria, tornando assim previsíveis, tanto as situações pelas quais os adolescentes passam como a maneira como eles reagem às mesmas. É recorrente a referência a uma "síndrome da adolescência”, remetendo à ideia de uma descrição fenomenológica típica da condição adolescente, suscetível de traduzir-se em problemas (AYRES, 1990).

Não se desconsidera que os acontecimentos da adolescência possam desencadear perturbações, instabilidades e atitudes que sejam coerentes com os estereótipos geralmente atribuídos a esse período. Afinal, o estabelecimento do que é próprio à idade, assim como suas transformações fisiológicas, de fato criam tanto circunstâncias geradoras de instabilidade (como o desenvolvimento da sexualidade, a escolha de um percurso após o período escolar, a maioridade 
civil, os ideais de independência, a transformação da afetividade, entre outras) quanto fornecem as significações que servem como referência para a construção dos sujeitos (OZELLA; AGUIAR, 2008). Porém, a orientação do olhar pelo viés da transitoriedade e do problema, como um vir a ser instável, tem como consequência prática o ofuscamento das questōes vivenciadas no presente (DAYRELL, 2003) e da diversidade de mediações que compõem as condições de saúde e os processos de adoecimento dos adolescentes.

O risco "é uma consequência da livre e consciente decisão de se expor a uma situação na qual se busca a realização de um bem ou de um desejo, em cujo percurso se inclui a possibilidade de perda ou ferimento físico, material ou psicológico" (MINAYO; SCHENKER, 2005, p. 708). Com o foco na possibilidade de danos, a construção do risco como objeto da saúde concentra seu significado em apenas uma das acepções desse conceito. Quando o risco é investigado na temática dos comportamentos, restringi-lo às chances de agravos deixa de contemplar as características e percepções pessoais, as motivaçôes e os constrangimentos envolvidos nas condutas, assim como as particularidades dos contextos nos quais cada indivíduo estrutura sua maneira de se comportar.

Para Chor (1999, p. 424), "é nessa dimensão que se encontram, provavelmente, as maiores lacunas do 'fazer' da saúde pública, ao não levar em conta o caráter não racional das escolhas de comportamento". Maturana (2009) é crítico à cisão entre a razão e as emoções, considerando-as as condições de possibilidade da primeira. São as emoções que definem nossos domínios de ação, enquanto a racionalidade é um recurso utilizado a posteriori, para justificar nossas atitudes. Todo argumento é racional, desde que aceitos os seus pressupostos. Assim, não seria uma atitude não racional que levaria a escolhas arriscadas para a saúde, mas as preferências inscritas no momento em que são tomadas.

$\mathrm{Na}$ verdade, todos sabemos isso na práxis da vida cotidiana, mas o negamos porque insistimos que o que define nossas condutas como humanas é elas serem racionais. Ao mesmo tempo todos sabemos que, quando estamos sob determinada emoção, mudamos de domínio de ação, há coisa que podemos fazer e coisas que não podemos fazer, e que aceitamos como válidos certos argumentos que não aceitaríamos sob outra emoção (MATURANA, 2009, p. 15).

As informações correntes sobre os comportamentos de risco em saúde não esgotam as razôes e as motivaçôes envolvidas em qualquer que seja a atitude em questão, nem tampouco é suficiente diante da variabilidade com que cada 
indivíduo responde àquilo que é estabelecido como arriscado. Cada um percebe e reage às situações cotidianas de acordo com sua história de interações nos contextos pelos quais circulam, dependendo de suas características pessoais, da forma como significa seus comportamentos e o dos outros e da emoção predominante em cada momento.

Maturana e Varela (1995) descrevem os seres vivos como sistemas determinados pela própria estrutura, ao que chamam autopoiese. Trata-se de um modo de organização do vivo que é autônomo, na medida em que produz a si mesmo, ao mesmo tempo em que depende dos recursos do meio para fazê-lo. $\mathrm{O}$ que nos acontece em determinado instante depende da nossa estrutura nesse instante, e é essa a propriedade da vida de reorganizar a sua estrutura, em sua constante relação com o meio, que permite aos seres a sua continuidade, mesmo diante daquilo que possa se constituir como ameaça. Assim, a mudança que algo externo desencadeia em um organismo depende do organismo em questão, e não desse algo externo.

Também em Canguilhem (1995), a noção de normatividade vital remete à vinculação dos seres vivos às condições em que a vida é possível, sendo a capacidade normativa dos organismos - isto é, de instituir as normas para si - que permite ao ser criar uma nova ordem fisiológica ou patológica diante de tensões com o meio.

Observar os indivíduos como separados ou contíguos ao ambiente (natural, social, cultural) em que estão necessariamente imersos resulta em profundas diferenças na apreensão dos comportamentos de risco. Quando se parte de uma suposta independência entre os fatores de risco e o indivíduo, a prevenção é pensada em termos de cuidados de evitação (MINAYO; SCHENKER, 2005), presumindo que, sem o contato com aquilo que oferece risco, garante-se a proteção contra o mesmo.

Se, por outro lado, assume-se a premissa de que a vida só é possível a partir de uma abertura para o meio em que ela se realiza, faz-se necessário pensar sobre a própria possibilidade de um fechamento para os riscos, e ainda se isso é algo realmente desejável. O contato com o mundo é aqui o principal recurso para o desenvolvimento da habilidade em responder a qualquer coisa que possa fazer "mal". E presumindo que o risco de nos depararmos com um risco é sempre muito alto, estaremos tão mais protegidos quanto mais atentos ao ambiente, às 
emoções que eles nos suscitam, e às maneiras como respondemos a eles. Faz-se assim necessário ampliar o escopo de análise sobre os comportamentos de risco em saúde, incluindo a amplitude de aspectos envolvidos na conduta humana.

\section{Resultados e discussão}

\section{Os adolescentes concretos}

A partir do quadro conceitual exposto acima, fundamentamos a metodologia e a análise da pesquisa de campo com os adolescentes. Perguntamos-lhes sobre suas motivações e as dos grupos nos quais circulam na adoção de duas práticas consideradas comuns no contexto da adolescência: o uso de álcool e outras drogas e a não utilização de métodos preventivos nas relações sexuais.

As entrevistas foram realizadas com sete adolescentes do sexo masculino e cinco do sexo feminino, todos entre 14 e 18 anos, matriculados em escolas públicas do município de Lagoa Santa. As entrevistas foram transcritas e as falas, categorizadas de acordo com a sistematização descrita por Bardin (1997) e então organizadas em torno de cinco categorias principais: a) definição de drogas; b) percepção sobre drogas ilícitas; c) motivação para uso de álcool; d) motivação para uso de outras drogas; e e) motivação para a não utilização de métodos contraceptivos.

Em relação à primeira categoria geral (definição de drogas), os adolescentes relataram diferentes percepções. $80 \%$ dos entrevistados consideram como droga as substâncias lícitas e ilícitas de uso recreativo, citando predominantemente o álcool e a maconha, referindo-se de forma desigual às outras drogas (cocaína, crack, ecstasy, oxi, loló, tabaco, entre outras), sendo que metade dos mesmos incluem em suas definições os remédios. 20\% dos entrevistados associa a definição de drogas somente às substâncias ilícitas. Para um adolescente do sexo masculino, de 16 anos, a percepção da droga vincula-se também à de vício, como relata: "muitas das vezes droga não é só essas ervas, essas coisas que eu falei, mas uma coisa que te prende muito, eu acho isso uma droga também”.

Em relação à segunda categoria (percepção sobre as drogas ilícitas), a maioria dos adolescentes vincula a proibição de determinadas drogas a efeitos prejudiciais à saúde das pessoas, como expresso nas falas: "acabam com a vida rápido" (masculino 16 anos) e "tem drogas que são perigosas, que afetam os neurônios das pessoas, fazem elas agir diferente, prejudicam a saúde" (feminino, 17 anos). Três adolescentes assumiram em seus discursos uma perspectiva crítica em torno 
dessa temática, mencionando os aspectos políticos, morais e sociais envolvidos na ilegalidade de algumas drogas e mostrando-se favoráveis à legalização da maconha. Por exemplo: "você sabia que eu sou a favor da legalização da maconha? Porque legalizando a maconha vai diminuir o número de tráfico de armas, vai diminuir o número de mortes, diminuir o número de uso, e com essa medida melhora a qualidade também" (feminino, 16 anos) e "eu acho que isso envolve muito o ganho financeiro, o governo da gestão... quanto mais, assim, também tem que considerar a coisa da ética familiar" (masculino, 17 anos).

A motivação para o uso de álcool entre os adolescentes entrevistados remete a três temas principais, quais sejam: a imagem associada ao consumo, como indica a fala "ah, não sei, acho que pra falar nossa, ah, eu sou descolado, eu bebo" (masculino, 15 anos); a diversão propiciada pelo efeito entorpecente, como declara uma entrevistada do sexo feminino, de 16 anos: "quando eu comecei a beber o que eu achava legal era isso, rir com os amigos, fazer piada, e tudo mais"; e, por último, como recurso de socialização, como expresso nos relatos "eu bebo mais forçado mesmo, que é só pra não ficar tão isolado da sociedade" (masculino, 15 anos) e "eu acho que muitas das vezes é a timidez mesmo, que faz usar.... porque você fica muito mais espontâneo" (feminino, 17 anos).

Em relação à motivação para uso de outras drogas, predomina nos discursos dos adolescentes entrevistados a associação da busca por drogas ilícitas à fuga de problemas pessoais e familiares, embora a maconha esteja vinculada, na percepção de alguns adolescentes (30\%), a efeitos de prazer e de tranquilidade, como declara um entrevistado do sexo masculino, de 16 anos:

[...] o prazer de você usar maconha é melhor quando você tem amizades e uma rodinha. Ali no meio, se você conhece todo mundo e é amigo, acho que a maconha te libera, você abre sua mente [...], e aí você sente um prazer de estar entre as pessoas, de sentir o que elas vão falar.

A não utilização de métodos preventivos nas relações sexuais é motivada, na percepção dos adolescentes entrevistados, pelas circunstâncias momentâneas, como relata um entrevistado do sexo masculino, de 15 anos: "ah, porque é um momento bom, é um momento de prazer, você gosta, então na hora você não pensa em parar"; pela irresponsabilidade contida nessa atitude, já que, em geral, todos os jovens sabem que devem usar; e, ainda, sobretudo na fala de adolescentes do sexo masculino, pelo julgamento público a que estariam submetidos aqueles que não consumassem o ato sexual, como indicado nas falas: "sexo ninguém quer 
fazer feio, né? Ainda mais no meio dos jovens, que propaga e tal. Vira fofoca fácil, má fama é fácil" (masculino, 16 anos) e "se na hora $\mathrm{H}$ ele falasse que não por causa da camisinha, a menina podia até sair falando que ele era gay, essas coisas. Ele ia pensar assim, como é que eu vou ficar diante dessa situação, não, agora que eu comecei eu tenho que terminar" (masculino, 15 anos).

Para os propósitos do nosso estudo, ressalta-se que o conhecimento sobre os riscos tornam-se muitas vezes secundários diante das preferências imediatas envolvidas em suas condutas, as quais variam nos diferentes relatos. Para alguns, é a diversão o que mais conta no consumo de bebidas alcoólicas, enquanto outros as utilizam como estratégia para se sentirem partícipes da situação vivenciada. Há adolescentes que relatam experiências prazerosas com a maconha, e que a preferem em relação ao álcool tanto pelos seus efeitos quanto pelos riscos envolvidos no uso de uma ou outra substância, ao passo que outros abominam o uso das drogas ilícitas, ao mesmo tempo em que declaram ter feito uso excessivo de álcool em determinadas circunstâncias sem maiores constrangimentos.

As diferentes vivências cotidianas dos adolescentes suscitam percepções mais ou menos críticas sobre as substâncias lícitas e ilícitas. Enquanto uns mostraram conhecimentos mais elaborados sobre o tema, outros basearam seus relatos no imaginário mais difundido do senso comum. Outras falas indicam como a probabilidade incerta de alguma consequência indesejada pode ser menos importante para o adolescente do que a certeza de um julgamento por parte de seus colegas, como no caso da consumação do ato sexual sem o uso de métodos preventivos.

É interessante notar que, exceto dois adolescentes que afirmaram fazer uso de álcool ocasionalmente, os demais entrevistados ressaltaram não ingerir álcool ou outras drogas, embora já houvessem experimentado ou utilizado durante algum período. Também sobre o não uso de preservativos, suas impressóes foram mais facilmente captadas quando referidas a ações dos adolescentes em geral, já que, em relação à própria conduta, a tendência foi mostrarem-se conscientes da importância do uso métodos preventivos e críticos daqueles que não o fazem. A recorrência dessa postura é indicativa da perspectiva moralizante na qual está geralmente inscrito o tratamento social dessas temáticas.

São muitos os exemplos que poderiam aqui ser trazidos para ilustrar a necessidade de uma visão mais crítica sobre o risco em saúde na adolescência. A 
perspectiva abstrata do risco e da adolescência traduz-se muitas vezes em tendências

modeladoras do comportamento e na responsabilização dos indivíduos pelos agravos em relação aos quais deveriam se preservar (AYRES et al., 2009). No entanto, cada indivíduo é singular e relaciona-se à sua maneira com os perigos e prazeres da vida. A experiência de uma pessoa pode não condizer com os perigos anunciados, o que levanta dúvidas sobre os cuidados que devem ser tomados (CASTIEL et al., 2010). E, na medida em que a moralização dos comportamentos de risco impede que sobre eles se fale abertamente, os adolescentes acabam desprovidos de informaçôes que podem lhes ser muito necessárias.

Ademais, vivência e experimentação são também cruciais para a construção das identidades. Quanto mais munidos de consciência crítica, autoestima e confiança, maiores as chances de crescimento, amadurecimento e formação da resiliência por parte dos adolescentes, aumentando assim a probabilidade de que os riscos não se traduzam em danos. A construção de alternativas frente às adversidades, o estabelecimento de novas práticas que não tragam danos à saúde e, enfim, a escolha de estilos de vida saudáveis, no sentido mais amplo da saúde, são possibilidades que, no lugar da culpabilização individual, podem ser propiciadas por atitudes construtivistas, que partem dos saberes e experiências daqueles para os quais se pretende construir estratégias de intervenção, valorizando-se as motivações pessoais e as emoções envolvidas em suas condutas.

O uso de álcool e outras drogas e a não utilização de métodos preventivos nas relações sexuais são questôes inscritas em contextos sociais e culturais mais amplos entre adultos e outras faixas etárias e que precisam ser consideradas para que seja viável uma real mudança nos quadros de adoecimento associados a tais comportamentos. Embora não tenha sido esse o foco do trabalho de campo, acreditamos ser necessário ter-se sempre em mente a relação mutuamente constitutiva entre indivíduo e meio no planejamento tanto de ações imediatas quanto nas estratégias a médio e longo prazo.

\section{Considerações finais}

Tomada como uma definição essencialmente técnica, como um conceito operacional e descritor da realidade, a noção de risco vem sendo reproduzida de forma predominantemente acrítica nos estudos em saúde (ALMEIDA FILHO, 1992). A tendência em não considerar as características redutoras das condições 
experimentais, bem como dos pressupostos que lhe são subjacentes, resulta na primazia de definições pragmáticas e intervenções técnicas em realidades essencialmente diversas e fluidas. $\mathrm{O}$ conhecimento abstrato é privilegiado diante de situações concretas, criando-se uma anterioridade da técnica em relação à vida (CZERESNIA, 2012).

A viabilidade da investigação sobre os riscos à saúde supõe uma inevitável redução dos aspectos dos fenômenos estudados. Por mais sofisticados que sejam os modelos de análise, como as abordagens que consideram simultaneamente fatores definidos em múltiplos níveis de organização - desde as dimensões macro da sociedade até os fatores micro do nível genético (DIEZ ROUX; ALVAREZ, 2010) -, sempre se faz necessário o recorte de variáveis, cuja relevância será determinada pelo olhar e pela pergunta do observador. A complexidade do comportamento humano não pode ser reduzida a projeções estatísticas, sendo imprescindível ampliar as bases de compreensão dos indivíduos e dos fenômenos que os constituem, para assim atuar de maneira abrangente em prol da saúde e da qualidade de vida.

Como sugerido pelos resultados do trabalho de campo exposto no artigo, a temática dos comportamentos de risco entre adolescentes envolve aspectos irredutíveis aos instrumentos quantitativos de pesquisa, sendo preciso aprimorar as estratégias de intervenção em saúde de forma a identificar as particularidades dos indivíduos e grupos para os quais se voltam e, assim, adequar as ações às necessidades dos mesmos.

Por fim, estando a conduta humana sempre implicada em um contexto ambiental, social e cultural, é preciso atentar para que a culpabilização individual não obscureça a responsabilidade conjunta da sociedade em fornecer aos adolescentes um ambiente saudável de desenvolvimento e maturação físicos e emocionais. Nem em um nem em outro dos extremos em que o pensamento moderno dividiu o mundo: a questão dos comportamentos de risco envolve a totalidade dos fenômenos e das estratégias capazes de propiciar uma efetiva melhoria nos quadros de adoecimento da população adolescente ${ }^{1}$.

\section{Referências}

ALMEIDA FILHO, N. A clinica e a Epidemiologia. Salvador: APCE-ABRASCO, 1992.

AYRES, J. R. de C. M. Adolescência e Saúde Coletiva: aspectos epistemológicos da abordagem programática. In: SCHRAIBER, L. B. Programação em Saúde Hoje. São Paulo: Hucitec, 1990. p. 139-182. 
AYRES, J. R. de C. M. et al. Risco, vulnerabilidade e práticas de prevenção e promoção

à saúde. In: CAMPOS et al. Tratado de Saúde Coletiva. Rio de Janeiro, Hucitec; Fiocruz, 2009. p. 375-417

BARDIN, L. Análise de conteúdo. Lisboa: Edições 70, 1997

CANGUILHEM, G. O normal e o patológico. Rio de Janeiro: Forense-Universitária, 1995.

CASTIEL, L. D. et al. Correndo o risco: uma introdução aos riscos em saúde. Rio de Janeiro: Editora Fiocruz, 2010

CHOR, D. Saúde pública e mudanças de comportamento: uma questão contemporânea. Cad. Saúde Pública, Rio de Janeiro, v. 15, n. 2, p. 423-425, abr. 1999.

CAMARGO JUNIOR, K. R. Racionalidades médicas: a medicina ocidental contemporânea. Rio de Janeiro: UERJ/IMS, 1993.

CZERESNIA, D. Categoria vida: reflexões para uma nova biologia. São Paulo: Hucitec, 2012.

CZERESNIA et al. Os sentidos da saúde e da doença. Rio de Janeiro: Fiocruz, 2013.

DAYRELL, J. O jovem como sujeito social. Rev. Bras. Educ. Rio de Janeiro, n. 24, set.-dez. de 2003.

DIEZ ROUX, A. V.; ALVAREZ, G. La necesidad de un enfoque multinivel en epidemiología: desafíos conceptuales y metodológicos. In: HARO, J. A. El planteamiento de una epidemiología sociocultural. Un diálogo en torno a su sentido, métodos y alcances. Buenos Aires: Lugar Editorial, 2010.

LUZ, M. T. Natural, Racional, Social - Razão Médica e Racionalidade Moderna. São Paulo: Hucitec, 1988.

MATURANA, H. Emoçôes e linguagem na educação e na política. Belo Horizonte: UFMG, 2009.

MATURANA, H.; VARELA, F. A árvore do conhecimento: as bases biológicas do entendimento humano. São Paulo: Psy II, 1995.

MINAYO, M. C. de S. O desafio do conhecimento: pesquisa qualitativa em saúde. São Paulo: Hucitex, 2010.

MINAYO, M. C. de S.; SCHENKER, M. Fatores de risco e de proteção para o uso de drogas na adolescência. Ciênc. saúde coletiva. Rio de Janeiro, v. 10, n. 3, p. 707-717 set. 2005.

ORGANIZAÇÃO MUNDIAL DA SAÚDE. Health for the World's Adolescents - A second chance in the second decade. World Health Organization: 2014

OZELLA, S.; AGUIAR, W. M. J. de. Desmistificando a concepção de adolescência. Cad. Pesqui., São Paulo, v. 38, n. 133, p. 97-125, abr. 2008

PERES, F.; ROSENBURG, C. P. Desvelando a concepção de adolescência/adolescente presente no discurso da Saúde Pública. Saúde soc. São Paulo, v. 7, n. 1, p. 53-86, jul. 1998. 
SAFATLE, V. O que é uma normatividade vital? Saúde e doença a partir de Georges Canguilhem. Sci. stud. São Paulo, v. 9, n. 1, p. 11-27, 2011.

SCHRAIBER, L. B. Pesquisa qualitativa em saúde: reflexões metodológicas do relato oral e produção de narrativas em estudo sobre a profissão médica. Revista de Saúde Pública, v. 29, n.1, p. 63-74, 1995.

\section{Nota}

${ }^{1}$ I. V. Chimeli participou da redação do artigo e desenvolvimento do trabalho de campo. M. J. Nogueira e V. T. Schall participaram da concepção do projeto. D. N. Pimenta colaborou com a revisão do texto. 


\section{Abstract}

\section{The abstraction of risk and the concreteness of the subject: a reflection of risk behaviors in the context of adolescence}

In times when a diversity of conditions resulting from unhealthy lifestyles and habits, characteristic of modern lifestyle, the notion of risk behavior becomes more and more present in the discourse and in health practices. In the context of adolescence studies, this issue has been analyzes by a series of investigations related to alcohol and other drugs use, smoking, inadequate diet, sedentary lifestyle, unprotected sexual activity and other behaviors that, when observed among young people, increase the risk to this particular phase of development. This article aims to critically discuss the construction of risk and adolescence as a concept and as an object of investigation in intervention and health care. It is structured as a qualitative study with individual and in depth interviews with 12 adolescents from Lagoa Santa city in Minas Gerais state, Brazil. The results point to different personal and emotional aspects raised by the youth usually not included in the research in the area, which nevertheless greatly influences the behavior of adolescents. We conclude that for the improvement and the resolution of public policies and actions towards the theme of risk behaviors, it is necessary to expand the scope of research on the concept of risks and theoretical perspectives that give them support.

Key words: risk behavior; adolescence; Collective Health. 